\title{
Melanoma: clinical, evolutive and histopathological characteristics of a series of 136 cases $^{*}$
}

\author{
Juliana Polizel Ocanha-Xavier ${ }^{1}$ \\ Mariângela Esther Alencar Marques ${ }^{3}$
}

\author{
José Cândido Caldeira Xavier-Junior²
}

DOI: http://dx.doi.org/10.1590/abd1806-4841.20186690

\begin{abstract}
BACKGROUND: The incidence of melanoma has been increasing in Brazil and all over the world. Despite improvements in diagnosis and treatment, mortality remains unchanged.

OвJеCтIVE: To associate clinical and histopathological aspects with the evolution of 136 cases of cutaneous melanoma.

MetHoDs: Retrospective cohort study that analyzed all patients diagnosed with melanoma during the period from 2003 to 2011, with at least 4 years follow up. Archived slides were analyzed to study histopathological variables (Breslow, ulceration, mitoses and histological regression). Medical records were used to retrieve clinical variables (age, sex, localization, time of appearance, diameter) and progression (metastases or death). Association measures were assessed by statistical analysis.

REsults: There was no statistically significant difference between groups according to age. Superficial spreading subtype showed lower Breslow $(0.5 \mathrm{~mm})$ than acral lentiginous and nodular subtypes ( 2 and $4.6 \mathrm{~mm}$ respectively), less ulceration and metastases (9.4\% against 50 and $70.6 \%)$. Nodular subtype had higher mitoses' median $\left(5.0 / \mathrm{mm}^{2}\right)$ than superficial spreading and lentigo maligna $\left(0.0 / \mathrm{mm}^{2}\right.$, for both). Regression was more frequent in superficial spreading and lentigo maligna subtypes. There were only deaths by melanoma in the acral group, however, there were deaths for other reasons in groups superficial spreading one, acral lentiginous one and lentigo maligna two.

StUDY LIMITATIONS: Use of medical records as a source of data to the study.

CONCLUSIONS: Superficial spreading subtype presents better prognosis indicators. Histological subtype should be considered in follow-up and treatment protocols of patients with cutaneous melanoma.
\end{abstract}

Keywords: Melanoma; Pathology; Prognosis; Survival rate

\section{INTRODUCTION}

In the United States between 1992 and 2014, the cases of melanoma increase in frequency around $1.4 \%$ per year (from 15 cases/ 100,000 inhabitants to 21.6 / 100,000). Besides, the number of melanoma deaths is around $2.7 / 100,000$ per year, what represents $1.7 \%$ of all cancer deaths. When restricted to the epidermis (in situ), melanoma patients have a five-year survival of approximately $98.3 \%$; however, when metastatic, the survival rate in five years is below $18 \%$. Mortality rates have remained stable despite improvements in diagnosis and the search for new treatments. ${ }^{1}$
In Brazil, the National Institute of Cancer (INCA) estimates 5670 new cases of melanoma for 2016 (INCA, 2016). ${ }^{2}$ According to Nasser (2011), in an epidemiological study performed in the southern region of the country, an increase in melanoma incidence and mortality in the last 30 years has been observed. In addition, a higher frequency of this malignancy was identified between women older than 50 years, being in the trunk the most affected site. ${ }^{3}$

Since 1969 melanoma cases have been grouped into four main clinical and pathological subtypes: superficial spreading (SS),

\footnotetext{
Received 08 November 2016.

Accepted 30 March 2017.

* Work conducted at Department of Pathology, Faculdade de Medicina de Botucatu, Universidade Estadual Paulista (FMB-UNESP), Botucatu (SP), Brazil. Financial support: FAPESP: 16013-5/2014.

Conflict of interest: None.

Clínica Tiradentes, Araçatuba (SP), Brazil.

Instituto de Patologia de Araçatuba, Araçatuba (SP), Brazil.

Department of Pathology, Universidade Estadual Paulista (UNESP), Botucatu (SP), Brazil.
}

MAILING ADDRESS:

Juliana Polizel Ocanha Xavier

E-mail: jpocanha@gmail.com

(C)2018 by Anais Brasileiros de Dermatologia 
lentigo maligna (LM), acral lentiginous (AL) and nodular (Nd); which are the background for the classification of the World Health Organization, besides the animal, desmoplastic, and mucosal subtypes. SS is the most frequent subtype (nearly $60 \%)^{4,5}$

The American Joint Cancer Committee $(\mathrm{AJCC})^{6}$ considered as predominant markers of worse prognosis Breslow, mitotic index and ulceration rate, and did not consider the histological subtype in the staging. On the other hand, the identification of genetic mutations in specific subtypes has made histological classification regain importance for the therapeutic decision of the cases. ${ }^{5}$

The objective of the present study was to evaluate a possible association between clinical, histopathological and progression variables for the different subtypes of melanoma, providing data that can be a reference in the guidance regarding follow-up and organization of public policies about melanoma in our country.

\section{METHODS}

It is a retrospective cohort in which a confidential analysis of the database of all cases of melanoma referred to surgical excision at the Faculdade de Medicina de Botucatu (UNESP - Botucatu - SP) from January 1, 2003 through December 31, 2011 was performed. The study was approved by the committee of ethics in research (CEP) of the Faculdade de Medicina - UNESP/Botucatu SP (CAAE 33405714.1.0000.5411/2014).

Data from the files were the source of clinical and progression data (age, affected site, diameter in centimeters, time to diagnosis, metastases, melanoma related deaths and death by other causes). Cases of the four main histological subtypes were studied, not being considered the cases of mucosal and desmoplastic melanoma, for example.

The location of the lesions was further divided into photoexposed and non-photoexposed areas. Axillae, trunk and upper thighs were considered as non-photoexposed areas. The remaining areas were considered photoexposed. Regarding AL group, due to the difficulty in establishing photoexposure, the site was detailed into hands and feet (plantar, subungual, heel, metatarsus and dorsum).

The slides were sent for second analysis by two pathologists and one dermatologist to complement all histological information of the primary lesion. Breslow, presence of ulceration, mitoses and histological regression were analyzed.

The patients who discontinued follow-up and those who did not have the histological subtype classification were excluded. The variable "time to diagnosis" could not be evaluated because patients with the subtype SS could not determine the exact time since the appearance of the first lesion.

Data were submitted to statistical analysis using the software SPSS version 21.0. Comparisons between the histological subtypes were performed using the chi-square test, Fisher's exact test, Kruskal-Wallis test and Dunn test. A P-value below 0.05 was considered statistically significant.

\section{RESULTS}

Out of a total of hundred and 95 patient diagnosed with melanoma in the nine years of the study (2003-2011), 136 patients remained after the exclusion criteria were applied. Sixty-seven cases were identified in males (49.3\%) and 69 in females (50.7\%), with a mean age of 57 years. Regarding the histological subtypes studied, the most common subtype was SS ( $\mathrm{n}=85 ; 62.5 \%)$, followed by AL $(\mathrm{n}=21 ; 15.5 \%), \mathrm{Nd}(\mathrm{n}=17 ; 12.5 \%)$ and $\mathrm{LM}(\mathrm{n}=13 ; 9.5 \%)$ (Figure 1$)$.

Mean age between the groups was: $\mathrm{SS}=58$ years, $\mathrm{AL}=$ 62 years, $\mathrm{Nd}=59$ years and $\mathrm{LM}=70$ years (table 1 ). There was a difference between the histological subtypes regarding diameter and metastases $(\mathrm{p}<0.001)$. In SS cases, median diameter was $1.0 \mathrm{~cm}$ against 2.3 and $2.0 \mathrm{~cm}$ for subtypes $\mathrm{AL}$ and $\mathrm{Nd}$, respectively. The presence of metastases was lower in SS (9.4\%) than in subtypes AL and $\mathrm{Nd}(50.0 \%$ and $70.6 \%)$. Melanoma related deaths were higher in the AL group (15\%). There were no melanoma deaths in the other melanoma subtypes. Besides, five patients died for other reasons: one patient in the SS group, to patients in the AL group and to patients in the LM group (Table 1).

Most lesions occurred in photoexposed areas (55\%) among the subgroups SS, Nd and LM and in individuals with the subtype $\mathrm{AL}$, most occurred on the plantar region (33\%), with only one case on the hand.

Breslow, ulceration, mitoses and regression were also different between the groups $(p<0.001)$. Median Breslow was of $0.5 \mathrm{~mm}$ against 2.0 and $4.6 \mathrm{~mm}$ for $\mathrm{AL}$ and $\mathrm{Nd}$. Ulceration was less frequent in the SS group. Besides, the Nd subtype showed a higher rate of mitoses (five mitoses $/ \mathrm{mm}^{2}$ ) than the SS and LM subtypes.

A higher rate of histological regression was seen in SS cases $(58.2 \%)$ and LM (69.2\%) than in cases of AL (20\%) and Nd $(12.5 \%)$ (Table 2).

\section{DISCUSSION}

The main result of this study was the identification of distinct clinical and histopathological characteristics for the different subtypes of melanoma in a population of the Brazilian inland.

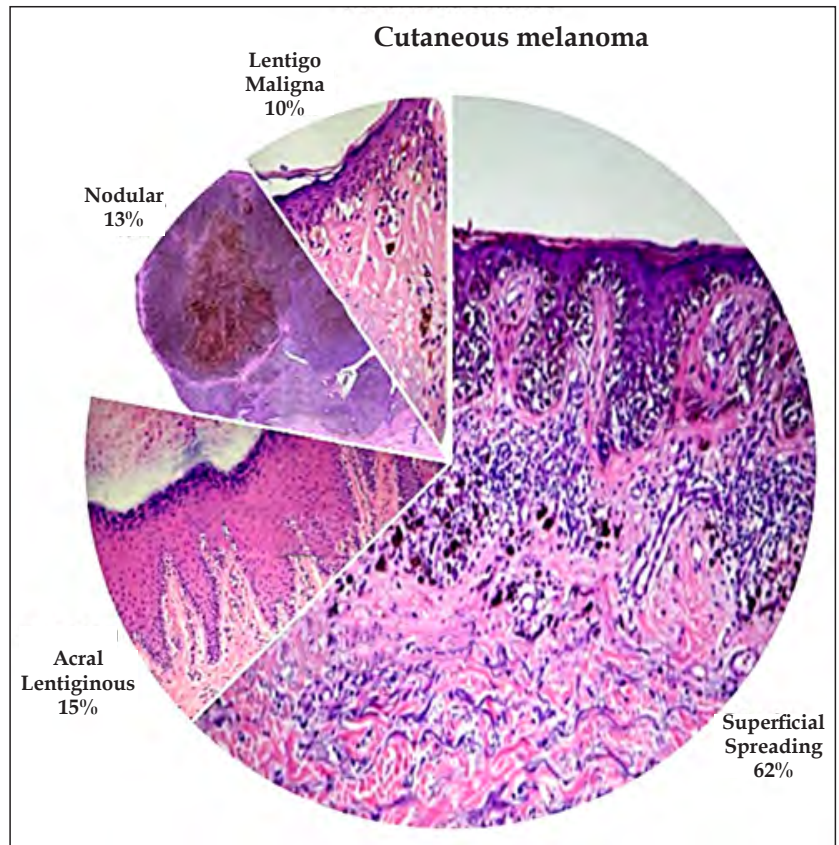

FIGURE 1: Distribution of the histological subtypes in the population studied (Hematoxylin \& eosin slides) 


\begin{tabular}{|c|c|c|c|c|c|}
\hline \multicolumn{6}{|c|}{ Subtype } \\
\hline Variables & Superficial Spreading & Acral Lentiginous & Nodular & Lentigo Maligna & P value ${ }^{1,2}$ \\
\hline Age $^{1}$ & $58.0(22.0-83.0)$ & $59.0(29.0-88.0)$ & $59.0(29.0-88.0)$ & $70.0(41.0-81.0)$ & $\mathrm{p}=0.05^{1}$ \\
\hline Diameter $^{1}$ & $1.0(0.1-5.0)$ a & $2.3(0.5-6.0) b c$ & $2.0(1.0-6.5) b c$ & $1.5(0.5-15.0)$ ac & $\mathrm{p}<0.001^{1}$ \\
\hline Metastases $^{2}$ & $8 / 85(9.4 \%)$ a & $10 / 20(50.0 \%)$ bc & $12 / 17(70.6 \%) b d$ & $4 / 13(30.8 \%)$ acd & $\mathrm{p}<0.001^{2}$ \\
\hline Deaths by other causes ${ }^{2}$ & $1 / 85(1.2 \%) \mathrm{a}$ & $2 / 20(10.0 \%) a b$ & $0 / 17(0.0 \%) a b$ & 2/13 (15.4\%) b & $\mathrm{p}=0.025^{2}$ \\
\hline Death by melanoma ${ }^{2}$ & $0 / 85(0.0 \%) \mathrm{a}$ & $3 / 20(15.0 \%) \mathrm{b}$ & $0 / 17(0.0 \%) a b$ & $0 / 13(0.0 \%) a b$ & $p=0.005^{2}$ \\
\hline
\end{tabular}

(1) Kruskal-Wallis test followed by Dunn test for multiple comparison. Data are in median (minimum-maximum). Similar letters indicate similarities between the groups (2)Chi-Square test or Fisher's exact test. Data are in median. Similar letters indicate similarities between the groups.

TABLE 2: Comparison between the clinical-pathological subtypes of cutaneous melanoma regarding histopathological aspects

\begin{tabular}{lccccc}
\hline Variables & Superficial Spreading & Acral Lentiginous & Nodular & Lentigo Maligna $^{\text {P value }}{ }^{1,2}$ \\
Breslow $^{1}$ & $0.5(0.0-10.0) \mathrm{a}$ & $2.0(0.0-25.0) \mathrm{bc}$ & $4.6(1.1-20.0) \mathrm{bc}$ & $0.7(0.0-8.0) \mathrm{ac}$ & $\mathrm{p}<0.001^{1}$ \\
Mitoses $^{1}$ & $0.0(0.0-21.0) \mathrm{a}$ & $2.0(0.0-50.0) \mathrm{ab}$ & $5.0(1.0-44.0) \mathrm{b}$ & $0.0(0.0-15.0) \mathrm{a}$ & $\mathrm{p}<0.001^{1}$ \\
Ulceration $^{2}$ & $11 / 79(13.9 \%) \mathrm{a}$ & $13 / 20(65.0 \%) \mathrm{bc}$ & $11 / 16(68.8 \%) \mathrm{bc}$ & $5 / 13(38.5 \%) \mathrm{ac}$ & $\mathrm{p}<0.001^{2}$ \\
Histological regression $^{2}$ & $46 / 79(58.2 \%) \mathrm{a}$ & $4 / 20(20.0 \%) \mathrm{b}$ & $2 / 16(12.5 \%) \mathrm{b}$ & $9 / 13(69.2 \%) \mathrm{a}$ & $\mathrm{p}<0.001^{2}$ \\
\hline
\end{tabular}

(1)Kruskal-Wallis test followed by Dunn test for multiple comparison. Data are in median (minimum-maximum). Similar letters indicate similarities between the groups. (2)Chi-Square test or Fisher's exact test. Data are in median. Similar letters indicate similarities between the groups.

The most frequent subtype was SS. In this study, it featured a lower Breslow, a smaller diameter, a small number of mitoses, ulceration, metastases and death rates by melanoma, explaining the better prognosis of this subtype. ${ }^{5}$ Besides, SS and LM showed higher rates of regression, a phenomenon that is controversial regarding its prognostic meaning. ${ }^{7}$

Lentigo maligna melanoma is the histological subtype more frequently related to sun exposure. ${ }^{8,9}$ The LM group presented with only one case in non-photoexposed area. Considering the patient's age and the slow growth of the tumor, besides the difficulty regarding complete excision of these tumors, conservative treatments for LM cases can be indicated. ${ }^{9}$ However, 13 patients (9.5\%) were identified in this group, and four cases (30.8\%) presented with metastases, in accordance to the highest estimates, despite the absence of melanoma deaths. ${ }^{10}$

Acral lentiginous melanoma is more common in non-Caucasian population, usually occurring in sites not exposed to the sun. ${ }^{11}$ In accordance to previous studies and with the African ancestry of the Brazilian population, the subtype AL presented a considerable number of patients, predominantly on the plantar region, what highlights the importance of the complete examination of patients on routine consultations. ${ }^{12,13}$ In comparison to the subtype SS cases, AL cases had lower rates of regression and higher frequency of melanoma deaths (15\%).

The literature is controversial regarding the aggressiveness of $\mathrm{AL}$, or if there is a delay in the diagnosis of this histological subtype due to the site affected, but studies indicate that for cases of acral melanoma, five-year survival is lower compared to the other histological subtypes, corrected for age and Breslow. ${ }^{14}$
Nodular melanoma has an approximate frequency between $10 \%$ and $30 \%$, with high rates of self-diagnosis due to the clinical history of rapid growth. ${ }^{15}$ Barbe et al. (2012) demonstrated a mean Breslow of $2.02 \mathrm{~mm}$, considerably lower than the $4.6 \mathrm{~mm}$ identified in this study, what can indicate a likely delay in diagnosis. ${ }^{16}$ Despite the association of the nodular group with metastases (70.6\%) these did not result in an increased frequency of melanoma deaths in the population studied, what could reflect the fact that they are described in the literature mainly located in lymph nodes, what could restrict the spread of the disease. ${ }^{17}$

The limitations of the study were that medical records were the source of data, with cases of a minimum four-year follow-up. Besides, the small population studied requires future studies to consolidate results.

\section{CONCLUSION}

This study demonstrated that the superficial spreading melanoma has better prognostic features compared to the acral lentiginous and nodular subtypes. Superficial spreading and lentigo maligna subtypes showed a higher prevalence of regression. In this context, the findings highlight the association of the histological subtype with the prognosis, wich may influence the approach and follow-up of patients. $\square$

\section{ACKNOWLEDGEMENTS}

Hélio R.C. Nunes for the statistical analysis. 


\section{REFERENCES}

1. Seer.cancer.gov [Internet]. Howlader N, Noone AM, Krapcho M, Rusakiewicz S, Chaput N, Altekruse SF, et al. SEER Cancer Statistics Review, 1975-2012, National Cancer Institute. Bethesda, MD. [cited 2015 May 18]. Available from: http://seer. cancer.gov/csr/1975_2012/.

2. Inca.gov.br [Internet]. Instituto Nacional de Câncer José Alencar Gomes da Silva. Coordenação de Prevenção e Vigilância. Estimativa 2016: incidência de câncer no Brasil. Rio de Janeiro: INCA; 2015. [acesso 28 maio 2016]. Disponível em: http:// www.inca.gov.br/estimativa/2016/estimativa-2016-v11.pdf.

3. Naser N. Cutaneous melanoma: a 30-year-long epidemiological study conducted in a city in southern Brazil, from 1980-2009. An Bras Dermatol. 2011;86:932-41.

4. de Vries E, Bray F, Coebergh JW, Cerroni L, Ruiter DJ, Elder DE, et al. Melanocytic tumours. In: LeBoit PE, Burg G, Weedon D, Sarasin A, editors. Skin tumours. Lyon: IARC Press; 2006. p. 49-120.

5. Greenwald HS, Friedman EB, Osman I. Superficial Spreading and Nodular Melanoma are distinct biological entities: a challenge to the linear progression model. Melanoma Res. 2012:22:1-8

6. Balch CM, Gershenwald JE, Soong SJ, Thompson JF, Atkins MB, Byrd DR, et al. Final version of 2009 AJCC Melanoma staging and classification. J Clin Oncol. 2009;27:6199-206

7. Ribero S, Gualano MR, Osella-Abate S, Scaioli G, Bert F, Sanlorenzo M, et al. Association of Histologic Regression in Primary Melanoma With Sentinel Lymph Node Status: A Systematic Review and Meta-analysis. JAMA Dermatol. 2015;151:1301-1307.

8. Gorman M, Hart A, Mathew B. A Left-Sided Prevalence of Lentigo Maligna: A UK Based Observational Study and Review of the Evidence. Dermatol Res Pract. 2015;2015:1-6.
9. Haenssle HA, Hoffmann S, Buhl T, Emmert S, Schön MP, Bertsch HP et al. Assessment of melanoma histotypes and associated patient related factors: basis for a predictive statistical model. J Dtsch Dermatol Ges. 2015;13:37-45.

10. Weinstock MA, Sober AJ. The risk of progression of lentigo maligna to lentigo maligna melanoma. Br J Dermatol. 1987;116:303-10.

11. Kasprzak JM, Xu YG. Diagnosis and management of lentigo maligna: a review. Drugs Context. 2015; 4:1-16.

12. Phan A, Touzet S, Dalle S, Ronger-Savlé S, Balme B, Thomas L. Acral lentiginous melanoma: histopathological prognostic features of 121 cases. $\mathrm{Br} \mathrm{J}$ Dermatol. 2007; 157:311-8.

13. Möhrle M, Lichte $\mathrm{V}$, Breuninger $\mathrm{H}$. Operative therapy of acral melanomas. Hautarzt. 2011;62:362-7.

14. Albreski D, Sloan SB. Melanoma of the feet: misdiagnosed and misunderstood. Clin Dermatol. 2009;27:556-63.

15. Moreau JF, Weinstock MA, Geller AC, Winger DG, Ferris LK. Individual and ecological factors associated with early detection of nodular melanoma in the United States. Melanoma Res. 2014;24:165-71.

16. Barbe C, Hibon E, Vitry F, Le Clainche A, Grange F. Clinical and pathological characteristics of melanoma: a population-based study in a French regional population. J Eur Acad Dermatol Venereol. 2012;26:159-64.

17. Cadili A, Dabbs K. Predictors of sentinel lymph node metastasis in melanoma. Can J Surg. 2010;53:32-6.

$\begin{array}{ll}\text { Juliana Polizel Ocanha Xavier } & \text { (D) ORCID 0000-0002-1200-3730 } \\ \text { José Cândido Caldeira Xavier Junior } & \text { (D) ORCID 0000-0003-0503-419X } \\ \text { Mariângela Esther Alencar Marques } & \text { (D) ORCID 0000-0001-6947-5627 }\end{array}$

How to cite this article: Ocanha-Xavier JP, Xavier-Junior JCC, Marques MEA. Melanoma: clinical, evolutive and histopathological characteristics of a series of 136 cases. An Bras Dermatol. 2018;93(3):373-6. 